\title{
Effect of plant density and water supply on wheat production
}

\author{
A.H. Ryhiner and M. Matsuda * \\ Institute for Land and Water Management Research (ICW), Wageningen, \\ the Netherlands
}

Accepted: 2 March 1978

Key words: wheat, production, crop density, water supply

\section{Summary}

A model is described to predict the dry matter production of a wheat crop. The photosynthetic rate of the crop surface is calculated from the amount of light and certain influences of the physical environment on photosynthesis, as crop density, water supply and meteorological conditions. The dominant role of the leaf surface resistance with regard to the final yield to be reached is apparent. Lowering the sowing density at limited water supply will give a more favourable grain/straw ratio.

\section{Introduction}

Data of sprinkler irrigation experiments as well as plant density experiments with wheat have been used in an analysis of the effect of crop density, water supply and meteorological conditions on dry matter production.

The dry matter production at different plant densities and various conditions of water supply can be calculated with a production model. Variations in crop density also affect the potential water requirements of the crop.

Stress conditions at a given water supply are present at an earlier stage of growth with increasing plant densities, affecting the distribution of dry matter over the various parts of the plant.

The given approach can be used for optimization of crop density and water supply in relation to crop yield for dry farming systems as well as for irrigated areas with a limited water supply.

\section{Available experimental data}

Available experimental data were taken from the logs of the Intitute's experimental station 'De Sinderhoeve' located at Renkum (province of Gelderland, the Neth-

* Visiting scientist from Kagawa University, Japan; now a Shinsu University, Matsumoto, Japan. 
erlands). They concern winter wheat (cv. Tadorna) in an experiment during 1970/ 1971 and spring wheat (cvs Peko and Jufy 1) in trials during 1961, 1962 and 1964. Of the spring wheat experiments some results on the effect of sprinkling irrigation were published by Toussaint $(1961,1962,1964)$ and de Vos \& Toussaint (1966). For the present study use was made of the original experimental data. The Tadorna experiment was carried out with five sowing densities $(72,96$, 120,168 and $240 \mathrm{~kg} \mathrm{ha}^{-1}$ ), the spring wheat experiments in the different years had a sowing density of 160,240 and $220 \mathrm{~kg} \mathrm{ha}^{-1}$, respectively.

The experimental field has a coarse sandy soil with $6.5 \%$ organic matter in the $40 \mathrm{~cm}$ top-layer. The available moisture content at the beginning of the growing season in the top $1 \mathrm{~m}$ is $100 \mathrm{~mm}$ of which about $72 \mathrm{~mm}$ is available from the mentioned humic top-layer. Root penetration was approximately $70 \mathrm{~cm}$.

Adequate and uniform fertilization and management practices were used to ensure healthy plant growth. The soil water content was determined weekly in the 1971 experiments by means of a gamma radiation transmission method during the growing season. The nature and method of soil density measurements were those described by Ryhiner \& Pankow (1969). During the 1961, 1962 and 1964

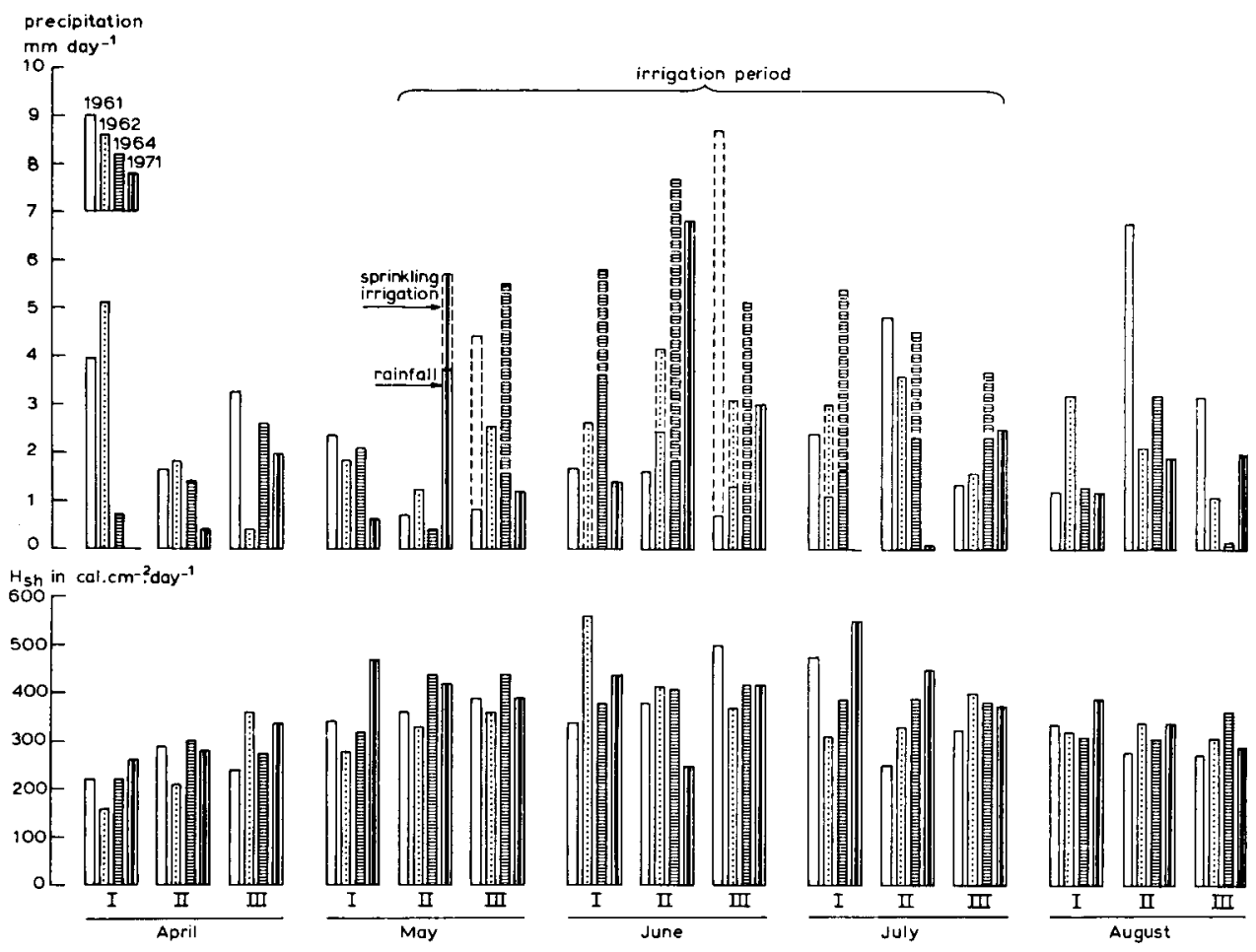

Fig. 1. Precipitation as well as sprinkling irrigation amounts expressed in $\mathrm{mm} \mathrm{day}^{-1}$ per 10-day period and incident short wave radiation in $\mathrm{cal} \mathrm{cm}-2$ day -1 in the growing seasons of 1961, 1962, 1964 and 1971 at the Sinderhoeve experimental station (Netherlands). 
experiments soil moisture determinations were performed by soil sampling. The meteorological data required for the calculations of potential evaporation such as short wave radiation, duration of bright sunshine, temperature, humidity, wind velocity and precipitation were measured daily at the meteorological observation field of the experimental station.

Fig. 1 gives some meteorological data and the amounts of sprinkling irrigation for the mentioned years. Crop growth was measured weekly as average height of the stand and the rate of development was estimated as the area of soil covered by plants. For the determination of dry matter production representative crop samples were obtained once per two weeks by random selection of a 1-metre row of plants. The results are presented as treatment averages.

\section{Dry matter production of wheat}

Dry matter production of field crops mainly depends on the intensity of solar radiation, the gross assimilation rate of individual leaves, the respiration rate, the size of the photosynthetic system, the nutritional status of the soil and the water supply. When a crop fully covers the soil surface and soil moisture is adequately available, photosynthesis can proceed at the potential rate under the prevailing environmental conditions. This potential production of a crop can be derived with de Wit's (1965) model, in which the potential production $\left(\mathbf{P}_{\mathrm{stand}}\right)$ is taken to be a function of incident light energy (in the range 0.4 to $0.7 \mu_{\mathrm{m}}$ ).

Considering physical limitations of the environment, Rijtema \& Endrödi (1970) proposed the following expression for the actual dry matter production $(\mathrm{P})$ per unit area of soil.

$\mathrm{P}=\alpha \frac{4.9}{\mathrm{r}_{\mathrm{a}}+1.7 \mathrm{r}_{\mathrm{s}}+\mathrm{r}_{\mathrm{m}}} \mathrm{S}_{\mathrm{c}} \mathbf{P}_{\mathrm{stand}}$ dry kg ha-1 day-1

where: $\alpha=$ an efficiency factor depending on the crop, being the ratio of potential net dry matter production over gross production of the standard crop

$\mathrm{r}_{\mathrm{a}}=$ exchange resistance between bulk air and the effective canopy surface in $\mathrm{s} \mathrm{cm}^{-1}$

$\mathrm{r}_{\mathrm{s}}=$ canopy surface resistance for water vapour transport; $1.7=$ ratio of the diffusion coefficients in air of water vapour and $\mathrm{CO}_{2}$; multiplication gives the surface resistance for $\mathrm{CO}_{2}$ transport in $\mathrm{s} \mathrm{cm}^{-1}$

$\mathrm{r}_{\mathrm{m}}=$ diffusion resistance for $\mathrm{CO}_{2}$ movement through the mesophyll in $\mathrm{s} \mathrm{cm}-1$, including the resistance to carboxylation and biochemical restraints, as influenced by temperature and leaf age in $\mathrm{s} \mathrm{cm}^{-1}$

$\mathrm{S}_{i} \quad=$ fraction of soil covered by the crop

$\mathbf{P}_{\mathrm{stand}}=$ gross potential production of a standard crop, as defined by de Wit (1965) in $\mathrm{kg} \mathrm{ha}^{-1}$ day-1, $^{-1}$

$4.9=r_{a}+1.7 r_{s}+r_{m}$ for de Wit's standard crop conditions 
The efficiency factor $\alpha$ is related to the respiration rate and the ratio of the potential gross production of the actual crop over the gross standard crop production. Values of $a$ for the wheat crops will be analysed in this study as the ratio net $P_{\text {pot }}$ over gross $P_{\text {stand }}$.

The exchange resistance $r_{a}$ is derived from tables given by Feddes (1971), using the data of crop height and wind velocity. It is assumed that in the turbulent moving air $\mathrm{r}_{\mathrm{a}}$ is equal for both water vapour and $\mathrm{CO}_{2}$ transport.

The surface resistance $\left(r_{s}\right)$ can be split into partial resistances:

$$
r_{\mathrm{s}}=\mathrm{r}_{\mathrm{s}}^{1}+\mathrm{r}_{\mathrm{s}}^{\psi} \quad \mathrm{s} \mathrm{cm}-1
$$

where $r_{s}{ }^{l}$ is a function of radiation intensity, and $r_{s} \psi$ is a function of leaf water potential. The resistance $r_{s}{ }^{l}$ was described in detail by Rijtema (1965) and Feddes (1971), and its values can be derived as a function of radiation intensity from their tables or graphs. In general, when a soil water stress is imposed a decrease in transpiration and an associated decrease in photosynthesis occurs. Rijtema (1965) did show that $r_{s}{ }^{\psi}$ depends on soil moisture content and soil water conductivity as well as plant properties and evaporative demand. For practical purposes $\mathbf{r}_{\mathrm{s}}{ }^{1}$ can be derived from actual evapotranspiration and the potential one by means of a formula given by Endrödi \& Rijtema (1969):

$$
r_{\mathrm{s}}^{\psi}=\frac{\Delta \mathrm{r}_{\mathrm{a}}+\gamma\left(\mathrm{r}_{\mathrm{a}}+\mathrm{r}_{\mathrm{s}}{ }^{\mathrm{s}}+\mathrm{r}_{\mathrm{s}}{ }^{\mathrm{c}}\right)}{\gamma}\left[\frac{\mathrm{E}_{\mathrm{pot}}-\mathrm{E}_{\mathrm{I}}}{\mathrm{E}_{\mathrm{ac}}-\mathrm{E}_{\mathrm{I}}}-1\right] \mathrm{s} \mathrm{cm}^{-1}
$$

where: $\Delta=$ the slope of the temperature-vapour pressure curve at air temperature in $\mathrm{mm} \mathrm{Hg}^{\circ} \mathrm{C}^{-1}$

$\gamma=$ psychrometer constant in $\mathrm{mm} \mathrm{Hg}^{\circ} \mathrm{C}^{-1}$

$r_{s}{ }^{c}=$ canopy resistance for water vapour related to soil cover in $\mathrm{s} \mathrm{cm}^{-1}$

$\mathrm{E}_{\mathrm{pot}}=$ potential evaporation in $\mathrm{mm} \mathrm{day}^{-1}$

$\mathrm{E}_{\mathrm{ac}}=$ actual evaporation in $\mathrm{mm}_{\text {day }}{ }^{-1}$

$\mathrm{E}_{\mathrm{I}}=$ evaporation of intercepted precipitation in $\mathrm{mm} \mathrm{day}{ }^{-1}$

Values of $r_{s}^{c}$, a resistance related to soil cover, are given by Rijtema \& Ryhiner (1966) and Feddes (1971). The potential evaporation from a crop surface can be calculated from standard meteorological data and the aerodynamic nature of the evaporating surface. With the procedure introduced by Penman (1948) and modified by Rijtema (1965) the potential evapotranspiration can be calculated and according to Endrödi \& Rijtema (1969) it can be expressed by:

$$
\mathrm{E}_{\mathrm{pot}}=\frac{\Delta+\gamma}{\Delta+\gamma\left(1+\frac{\mathrm{r}_{\mathrm{s}}^{\mathrm{l}}+\mathrm{r}_{\mathrm{s}}^{\mathrm{c}}}{\mathrm{r}_{\mathrm{a}}}\right)}\left[\mathrm{E}_{\mathrm{wet}}-\mathrm{E}_{\mathrm{I}}\right]+\mathrm{E}_{\mathrm{I}} \quad \mathrm{mm} \mathrm{day}^{-1}
$$

where $E_{\text {wet }}$ in $\mathrm{mm}_{\text {day }}^{-1}$ is the evaporation of a wet surface with the same dimensions and shape as the crop considered.

The actual evapotranspiration $\left(E_{a c}\right)$ is calculated from water balance data and $E_{I}$ from the distribution of the precipitation during the balance period (Rijtema, 1965).

Returning to Eq. 1, $\mathrm{r}_{\mathrm{m}}$ remains to be determined. In first instance it is assumed 

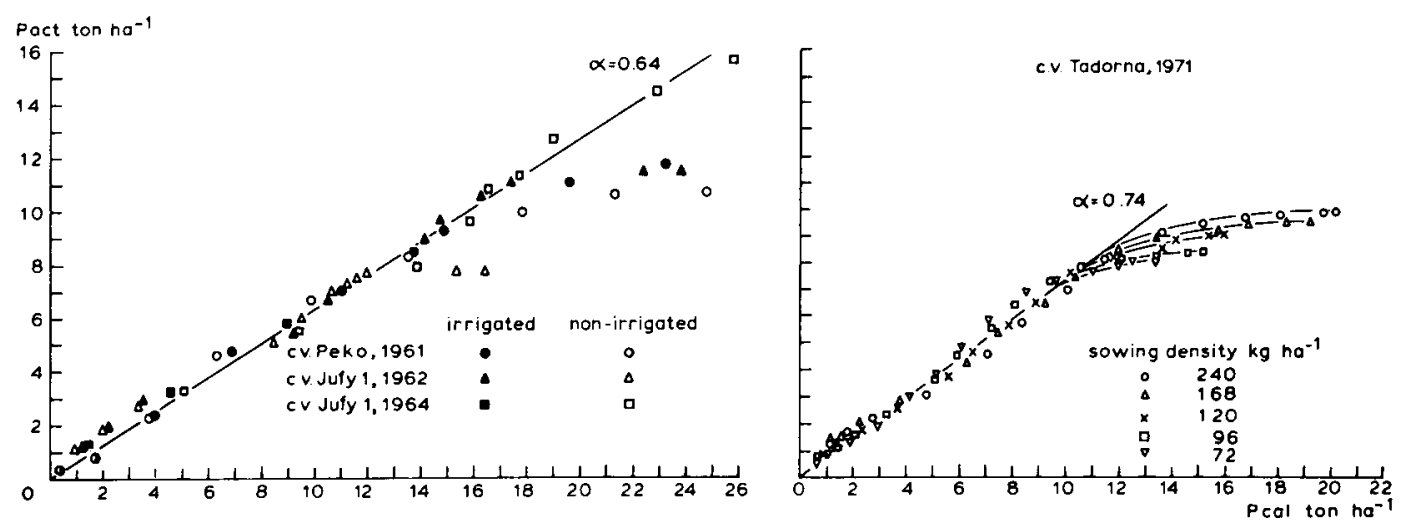

Fig. 2. The relation between calculated gross production and the data obtained from periodical harvests.

that it has the value of $4.4 \mathrm{~s} \mathrm{~cm}^{-1}$ (Rijtema \& Endrödi, 1970). The actual production rate can provide a reasonable estimate of the mesophyll resistance especially towards the end of growth cycle when this resistance becomes a substantial one.

Plotting the data of actual dry matter production, as obtained from the periodical harvests, against $\left[4.9 /\left(r_{a}+1.7 r_{b}+4.4\right)\right] S_{c} P_{s t a n d}$ gives the efficiency factor $\alpha$ as the tangent at the origin of the curve.

The dry matter production derived from periodical harvests is plotted in Fig. 2 against the calculated production. The slope of the linear part of the curves is $a$ and equals 0.74 for winter wheat and 0.64 for spring wheat.

The various points at which the curves reach the inflexion agree with the production levels of the various treatments and correspond to the point in time at which the leaves began to senesce.

There is no indication that the results of any treatment departed from the general relationship. The value of the efficiency factor a ranges from 0.64 to 0.74 . This variation must be ascribed to the fact that in the periodical harvests production of the root system was not taken into account. In the case of winter wheat the root system already develops in fall and early spring, so less assimilated dry matter is needed for the development of the root system in spring. As the calculations pertain to the period of April to August it is evident that $a$ is larger for winter wheat than for spring wheat.

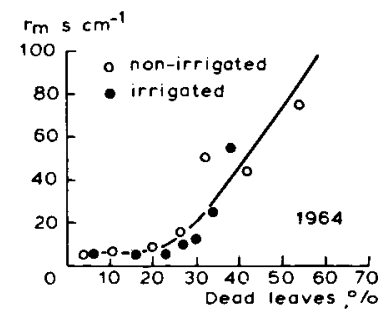

Fig. 3. The relation between $r_{m}$ and the percentage of dead leaves in 1964. 


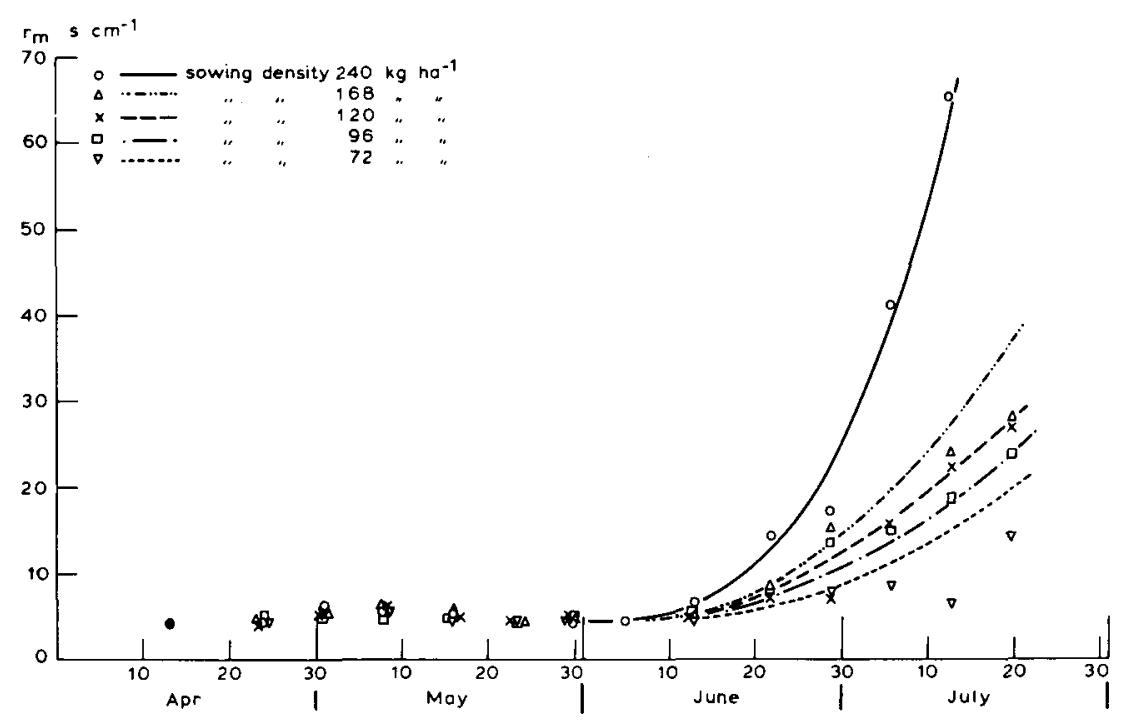

Fig. 4. Comparison of calculated mesophyll resistances for winter wheat in $1971\left(r_{m}\right)$, as a function of time. The lines are calculated with the aid of dying-off data, from Fig. 3, whereas the points were calculated by back solution of Eq 1 .

An analysis of the increase of $r_{m}$ near senescence can be made by back solution of Eq. 1.

Relating the calculated $r_{m}$ values with available dying-off data of the crop in 1964 (Fig. 3) offers the possibility to apply this relationship to the data of the Tadorna crop. The calculated course of $r_{m}$ derived with the aid of Fig. 3 obtained from the dying-off data for the different Tadorna crop densities is given by the curves in Fig. 4, whereas the data obtained by back calculation of Eq. 1 are given by the points.

Although no great accuracy can be claimed for these calculated data, they reveal some interesting features. When the mature crop approaches ripening the magnitude of the mesophyll resistance increases considerably, whereas up to maturation the value remains constant at some 4.4 tot $5.0 \mathrm{~s} \mathrm{~cm}^{-1}$.

A clear response of the seasonal course of $r_{m}$ to population density is shown. Probably earlier maturation and a competition effect due to stress conditions may have contributed to these responses.

The given data indicate the dominant role of leaf surface resistances in the final yield to be reached. It must be remembered that the activity of the effective leaf surface, as well as its extent, is a determinant of grain yield. High densities alone may not compensate completely high leaf resistances, which confirms Matsuda's (1965) experimental results with a rice crop. 


\section{Crop density, water use and production}

Plant growth is closely related to plant evaporation. Although the relationship between production rate and evaporation rate is rather complicated, for practical purposes it is possible to use simple relations between accumulated photosynthesis product and cumulative plant evaporation. In a way similar as proposed by Bierhuizen \& Slatyer (1965) and Rijtema (1966) a linear relationship between total dry matter production and the ratio total evapotranspiration over mean vapour pressure deficit is assumed, resulting in:

$$
\mathbf{P}_{\text {ac.tot }}=\mathbf{a} \frac{\mathbf{E}_{\text {ac.tot }}}{\Delta \mathbf{e}}
$$

where: $\mathbf{P}_{\mathrm{ac} . t \mathrm{tat}}=$ accumulated dry matter production in $\mathrm{kg} \mathrm{ha}^{-1}$

$\mathrm{E}_{\mathrm{ac} . \mathrm{tot}}=$ accumulated actual evapotranspiration in $\mathrm{mm}$

$\Delta \mathrm{e}=$ mean vapour pressure deficit in mbars

a $\quad=$ crop constant

When assuming that potential production is achieved under conditions of potential evaporation Eq. 5 can be reduced to:

$$
P_{\text {ac.tot }}=P_{\text {pot.tot }} \frac{E_{\text {ac.tot }}}{E_{\text {pot.tot }}}
$$
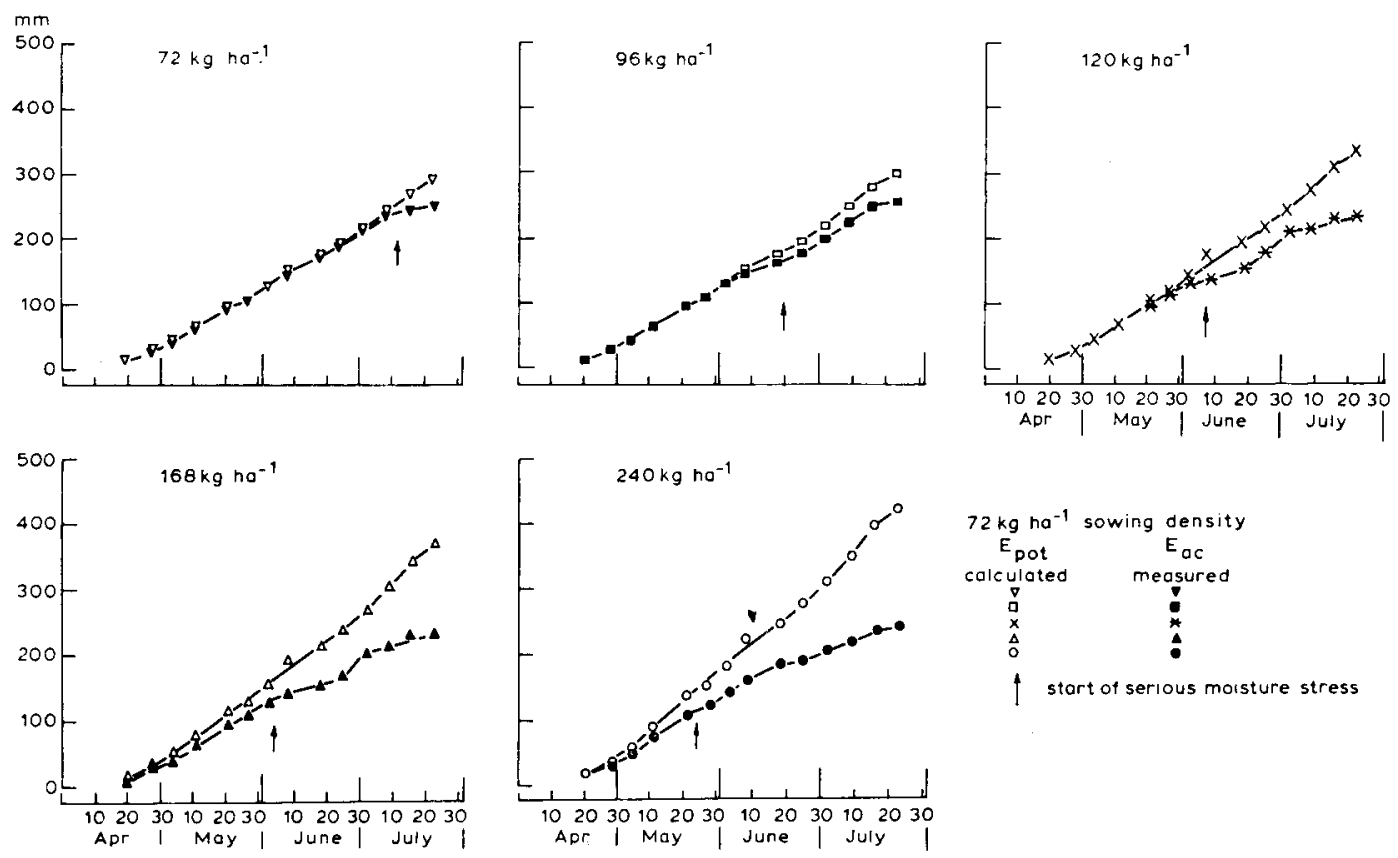

Fig. 5. Potential $\left(\mathrm{E}_{\mathrm{pot}}\right)$ and actual $\left(\mathrm{E}_{\mathrm{ac}}\right)$ evaporation of winter wheat during the growing season of 1971 for the given sowing densities. 


\section{PLANT DENSITY, WATER SUPPLY AND WHEAT PRODUCTION}

Values of $\mathrm{P}_{\text {pot.tot }}$ can be calculated with Eq. 1 for conditions of optimum water supply, and $\mathrm{E}_{\text {pot. tot }}$ with Eq. 4.

Decreasing crop density affects both $\mathrm{P}_{\text {pot.tot }}$ and $\mathrm{E}_{\text {pot.tot }}$ by the decreased soil cover. In particular under conditions of a limited water supply, for instance in dry farming or when irrigation water supply is limited, it is necessary to optimize the crop densities to the water resources.

The Tadorna experiment gives an example of the effect of crop density in relation to limited water supply. Fig. 5 gives the cumulated data of calculated potential and measured actual evapotranspiration in relation to crop density. With increasing density a serious moisture stress develops at an earlier date. It is shown in Table 1 that the mean soil cover during growth increases with sowing density, resulting in different values for $\mathrm{P}_{\text {pot.tot. }}$. It is interesting to note that although the minimum and maximum sowing densities differ a factor 3.3 , the potential productions in these cases differ only a factor 1.7 .

The values of $\mathrm{E}_{\text {pot.tot }}$ also increase with increasing sowing density, whereas $\mathrm{E}_{\mathrm{ac} \text {.tot }}$ is almost constant because of the limited water supply.

The calculated $\mathrm{P}_{\text {ac.tot }}$ values, obtained from Eq. 6, agree fairly well with the measure data. Since the severe moisture stress conditions at the high plant densities occured before anthesis (Fig. 5), the grain/straw ratio is unfavourably affected, resulting in an only slowly increasing grain production with increasing crop density. The additional grain production obtained by means of an increasing sowing density is minimal. It might even be expected that under more severe stress conditions the grain production would drop with increasing sowing densities.

Fig. 6 gives the course of the calculated dry matter production as curves, compared with the data of the periodical harvests as points, for both irrigated and non-irrigated spring wheat in the years 1961, 1962 and 1964. The deviation between irrigated and non-irrigated fields demonstrates clearly the effect of stress
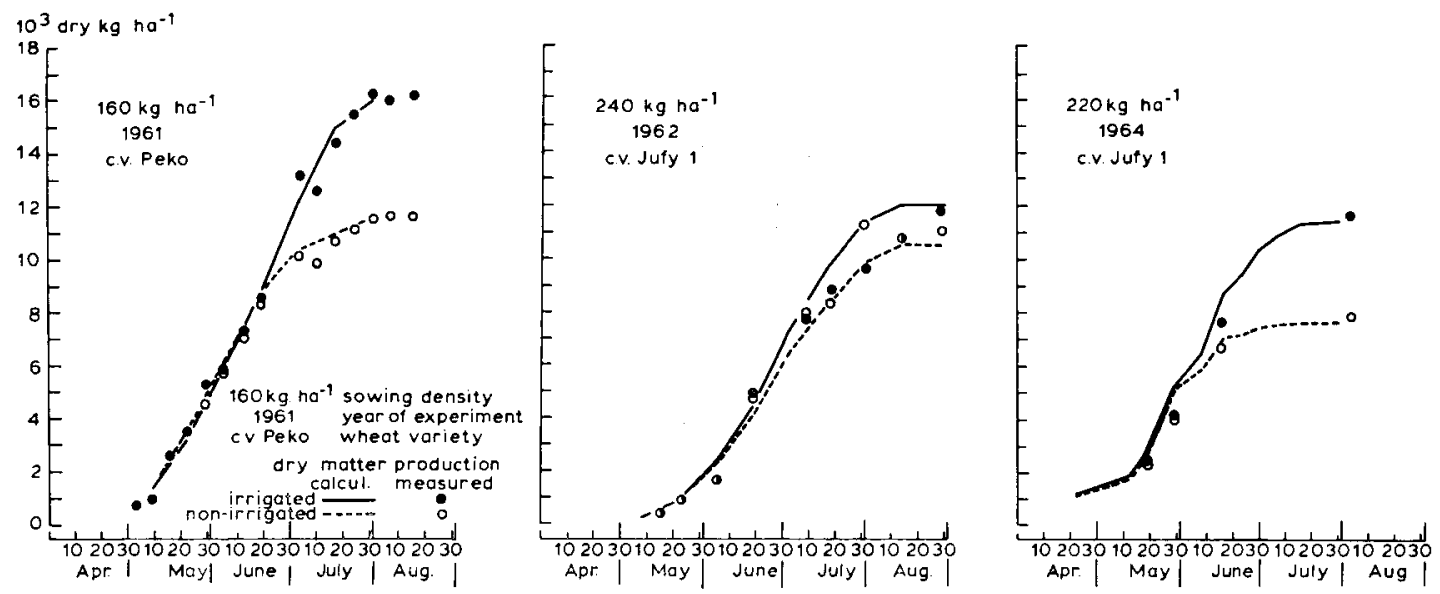

Fig. 6. Calculated and observed dry matter production of irrigated and non-irrigated spring wheat in 1961, 1962 and 1964.

Neth. J. agric. Sci. 26 (1978) 
A. H. RYHINER AND M. MATSUDA

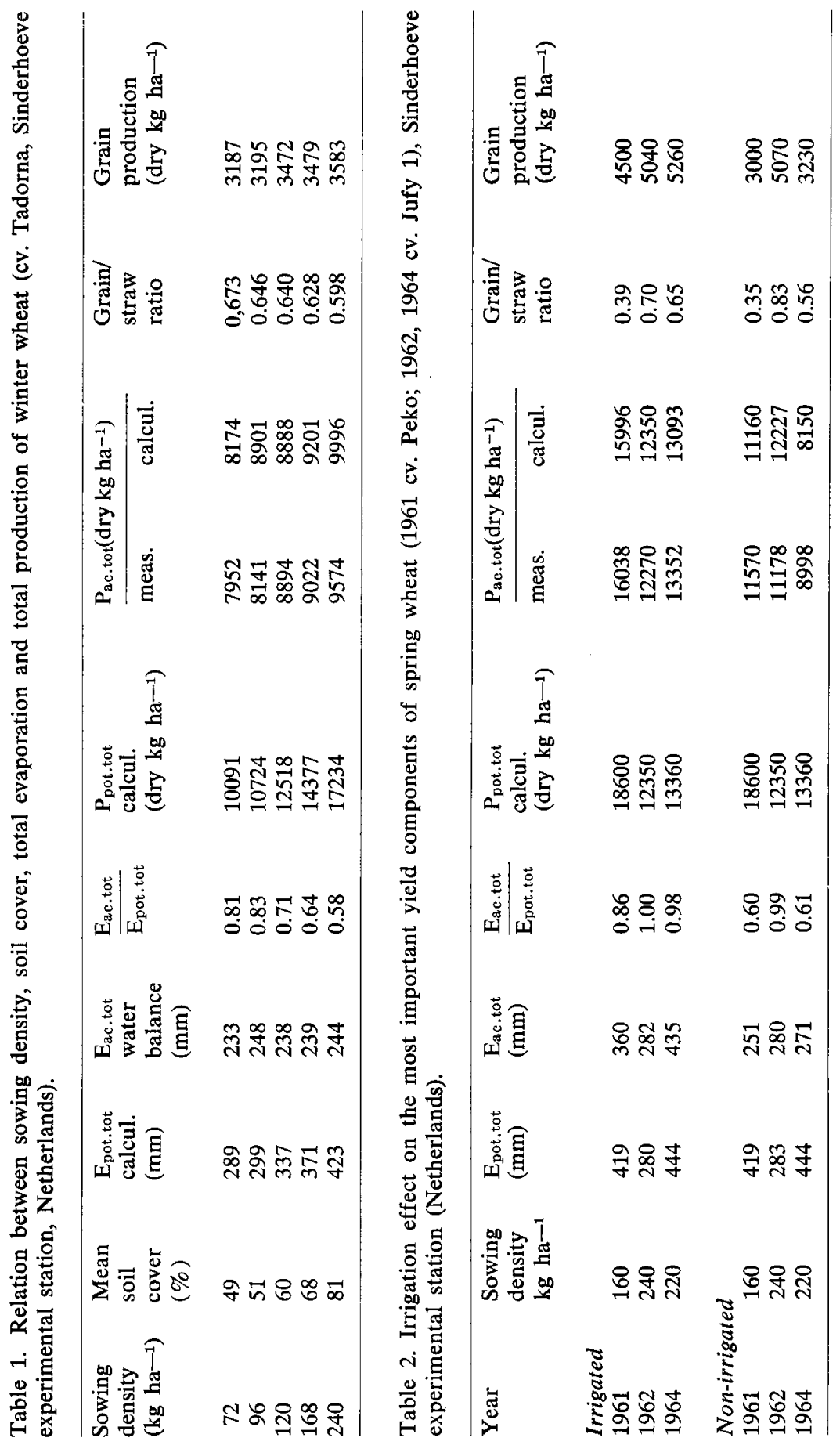




\section{PLANT DENSITY, WATER SUPPLY AND WHEAT PRODUCTION}

conditions on dry matter production. In Table 2 the irrigation effects on the most important yield components of the spring wheat experiments are given. The data show that with the use of Eq. 6 a fair appraisal of dry matter production can be obtained. The grain/straw ratio is favourably affected by irrigation in the years with stress conditions. Irrigation in the wet summer of 1962 mainly resulted in a larger straw production.

\section{Conclusions}

The method for the calculation of photosynthesis of leaf canopies, as proposed by de Wit (1965) and modified by Rijtema \& Endrödi (1970) gives a fair approach to the dry matter production of spring and winter wheat. Sowing densities affected both the potential water requirement of the crop and the potential production of dry matter.

Actual dry matter production could also be calculated from calculated potential production and the ratio $\mathrm{E}_{\text {ac.tot }}$ over $\mathrm{E}_{\text {pot.tot }}$.

Lowering crop density at a given water supply resulted in a more favourable distribution of dry matter over grain and straw due to less severe stress conditions.

The results are important for the optimization of the relation between crop density, water supply and dry matter and grain production in dry farming systems and irrigated areas with a limited water supply.

\section{References}

Bierhuizen, J. F. \& R.O. Slatyer, 1965. Effect of atmospheric concentration of water vapour and $\mathrm{CO}_{2}$ in determining transpiration - photosynthesis relationships of cotton leaves. Agric. Neth. 2: 259-270.

Endrödi, G. \& P. E. Rijtema, 1969. Calculation of evapotranspiration from potatoes. Neth. J. Agric. Sci. 17: 283-299/Tech. Bull. ICW 69.

Feddes, R. A., 1971. Water heat and crop growth. Meded. LandbHogesch. Wageningen 71-12; $184 \mathrm{pp}$.

Matsuda, M., 1965. On the micrometeorological elements and E-T in each growing stage of paddy rice plant. IV. Transpiration control and yield of rice plant. Trans. AESJ 12: 25-29

Penman, H. L., 1948. Natural evaporation from open water, bare soils and grass. Proc. Roy. Soc. Lond. A 193: 120-145

Rijtema, P. E., 1965. An analysis of actual evapotranspiration. Agric. Res. Rep. 659. Pudoc Wageningen, $107 \mathrm{pp}$.

Rijtema, P. E., 1966. Transpiration and production of crops in relation to climate and irrigation. Tech. Bull. ICW 44; 25 pp.

Rijtema, P. E. \& G. Endrödi, 1970. Calculation of production of potatoes. Neth. J. Agric. Sci. 18: 26-36 / Tech. Bull. ICW 70.

Rijtema, P. E. \& A. H. Ryhiner, 1966. De lysimeters in Nederland (III). Aspecten van verdamping en resultaten van verdampingsonderzoek. Versl. Meded. Hydrol. Comm. TNO 14 (1968) 86-149 / Meded. ICW 108.

Ryhiner, A. H. \& J. Pankow 1969. Soil moisture measurement by gamma transmission methods. J. Hydrol. 9: 194-205/Tech. Bull. ICW 66.

Toussaint, C. G., 1961, 1962, 1964. Internal Reports ICW.

Vos, N. M. de \& C. G. Toussaint 1966. De vochtvoorziening van zomergranen op droogtegevoelige zandgrond. (The effect of sprinkling irrigation on the yield of cereals grown on high sandy soils.) Versl. Landbouwk. Onderz. 679. Pudoc, Wageningen, 29 pp.

Wit, C. T. de, 1965. Photosynthesis of leaf canopies. Agric. Res. Rep. 663. Pudoc, Wageninningen, $57 \mathrm{pp}$. 